\title{
Large-scale field trial of attractive toxic sugar baits (ATSB) for the control of malaria vector mosquitoes in Mali, West Africa
}

\author{
Mohamad M. Traore', Amy Junnila', Sekou F. Traore1, Seydou Doumbia', Edita E. Revay' ', Vasiliy D. Kravchenko², \\ Yosef Schlein ${ }^{3}$, Kristopher L. Arheart ${ }^{4}$, Petrányi Gergely ${ }^{5}$, Rui-De Xue ${ }^{6}$, Axel Hausmannn, Robert Beck ${ }^{5}$, \\ Alex Prozorov ${ }^{1}$, Rabiatou A. Diarra ${ }^{1}$, Aboubakr S. Kone ${ }^{1}$, Silas Majambere', John Bradley ${ }^{8}$, John Vontas ${ }^{9,10}$, \\ John C. Beier ${ }^{4}$ and Günter C. Müller ${ }^{1 *}$
}

\begin{abstract}
Background: The aim of this field trial was to evaluate the efficacy of attractive toxic sugar baits (ATSB) in Mali, where sustained malaria transmission occurs despite the use of long-lasting insecticidal nets (LLINs). ATSB bait stations were deployed in seven of 14 similar study villages, where LLINs were already in widespread use. The combined use of ATSB and LLINs was tested to see if it would substantially reduce parasite transmission by Anopheles gambiae sensu lato beyond use of LLINs alone.

Methods: A 2-day field experiment was conducted to determine the number of mosquitoes feeding on natural sugar versus those feeding on bait stations containing attractive sugar bait without toxin (ASB) — but with food dye. This was done each month in seven random villages from April to December 2016. In the following year, in seven treatment villages from May to December 2017, two ATSB bait stations containing the insecticide dinotefuran were placed on the outer walls of each building. Vector population density was evaluated monthly by CDC UV light traps, malaise traps, pyrethrum spray (PSCs) and human landing catches (HLCs). Female samples of the catch were tested for age by examination of the ovarioles in dissected ovaries and identification of Plasmodium falciparum sporozoite infection by ELISA. Entomological inoculation rates (EIR) were calculated, and reductions between treated and untreated villages were determined.
\end{abstract}

Results: In the 2-day experiment with ASB each month, there was a lower number of male and female mosquitoes feeding on the natural sugar sources than on the ASB. ATSB deployment reduced CDC-UV trap female catches in September, when catches were highest, were by $57.4 \%$ compared to catches in control sites. Similarly, malaise trap catches showed a $44.3 \%$ reduction of females in August and PSC catches of females were reduced by $48.7 \%$ in September. Reductions of females in HLCs were lower by $19.8 \%$ indoors and $26.3 \%$ outdoors in September. The high reduction seen in the rainy season was similar for males and reductions in population density for both males and females were $>70 \%$ during the dry season. Reductions of females with $\geq 3$ gonotrophic cycles were recorded every month amounting to $97.1 \%$ in October and $100.0 \%$ in December. Reductions in monthly ElRs ranged from 77.76

\footnotetext{
*Correspondence: guntercmuller@hotmail.com

${ }^{1}$ Malaria Research and Training Centre, Faculty of Medicine, Pharmacy

and Odonto-Stomatology, University of Sciences, Techniques

and Technology of Bamako, BP 1805, Bamako, Mali

Full list of author information is available at the end of the article
}

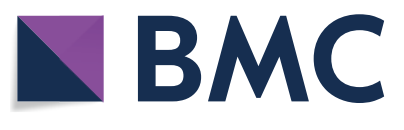

(c) The Author(s) 2020. This article is licensed under a Creative Commons Attribution 4.0 International License, which permits use, sharing, adaptation, distribution and reproduction in any medium or format, as long as you give appropriate credit to the original author(s) and the source, provide a link to the Creative Commons licence, and indicate if changes were made. The images or other third party material in this article are included in the article's Creative Commons licence, unless indicated otherwise in a credit line to the material. If material is not included in the article's Creative Commons licence and your intended use is not permitted by statutory regulation or exceeds the permitted use, you will need to obtain permission directly from the copyright holder. To view a copy of this licence, visit http://creativeco mmons.org/licenses/by/4.0/. The Creative Commons Public Domain Dedication waiver (http://creativecommons.org/publicdomain/ zero/1.0/) applies to the data made available in this article, unless otherwise stated in a credit line to the data. 
to $100.00 \%$ indoors and $84.95 \%$ to $100.00 \%$ outdoors. The number of sporozoite infected females from traps was reduced by $97.83 \%$ at treated villages compared to controls.

Conclusions: Attractive toxic sugar baits used against Anopheles mosquitoes in Mali drastically reduced the density of mosquitoes, the number of older females, the number of sporozoite infected females and the EIR demonstrating how ATSB significantly reduces malaria parasite transmission.

Keywords: Anopheles gambiae, ATSB, Vector control, Mali, Sugar feeding

\section{Background}

Malaria is one of the most devastating diseases in Africa where it is mostly transmitted by Anopheles gambiae sensu stricto (s.s.), Anopheles coluzzii, Anopheles funestus, and Anopheles arabiensis [1]. In 2017, the World Health Organization (WHO) estimated that there were 219 million cases of malaria globally [2], and that 'no significant progress in reducing global malaria cases was made in recent years' [2]. There is a clear need to develop and integrate new vector control strategies to further reduce malaria transmission [3-5]. Current vector control methods include the use of long-lasting insecticidal nets (LLINS), indoor residual spraying (IRS), and larval control [6-8]. Integrated vector management (IVM) seeks to optimize the use current interventions and to integrate them with new methods as they become available $[6,9]$ especially in problematic areas of sustained transmission despite the scale-up of LLINs or IRS [10-14].

Sugar-feeding is critical to the survival of African malaria vectors [15-18] and the availability of sugar sources in the local environment is a key regulator of mosquito population dynamics and, therefore, vectorial capacity $[15,16]$. The attractive toxic sugar bait (ATSB) method is a mosquito control system that exploits the need for both male and female mosquitoes to take vital sugar meals $[19,20]$. It comprises a bait, attractive to the species of interest (usually with a fruit or flower scent), and contains an oral toxin mixed with sugar as a feeding stimulant [21]. There are many different classes of oral toxins that can be used for ATSB, including carbamates, pyrethroids, neonicotinoids, spinosyns, borates, biopesticides and double-stranded RNA [21-26]. ATSB has been applied as a spray on vegetation and blossoms [21, 22, 27] and has also been incorporated into bait stations which can be hung walls of houses or inside cisterns and drains [22]. Excellent mosquito control has been achieved in small-scale experiments with ATSB in Israel where it was developed and extensively tested against numerous species [21, 23, 24-26]. The potential of ATSB to control mosquitoes was also demonstrated in successful field experiments in Mali $[23,28,29]$ and in the USA [23, 30].

The current field trial in Mali tested the potential impact of ATSB by different criteria including vector densities, the rate of biting on humans, the proportion of 'old' females that passed at least three or more egg laying cycles, sporozoite infection rate, and EIR. An obvious advantage of ATSB is its function outdoors against exophilic Anopheles spp., which are not directly exposed to IRS and LLINs, and can be effective against insecticide resistance and the behavioural plasticity shown by Anopheles in response to the scale-up of indoor interventions [11-14]. It is expected that in the long-term integrated vector management (IVM) programme that combines both ATSB and currently used LLINs would substantially contribute to the reduction of malaria transmission.

\section{Methods \\ Experimental villages and characterization of mosquito populations}

In the Keyes Province of Mali $(14.115,-10.568611)$, West Africa 14 villages accessible by car, and within $10 \mathrm{~km}$ of the Niger River were selected in 2016 (see Additional file 1: Fig. S1) and baseline entomological surveys were conducted (unpublished). The dominant mosquito species were $A n$. coluzzii and An. gambiae s.s. (unpublished data). In the field trial of ATSB in 2017, seven of the 14 villages, were allocated to treatment and seven were control villages. All of the villages had $>90 \%$ LLINs coverage and no other anti-mosquito interventions (including mass drug administration MDA), determined by a separate social science team inspecting homes and talking to residents. These 14 villages (Table 1) were randomly assigned to treatment and parallel control groups. Villages were assigned a random number in Microsoft Excel, odd numbers were assigned to the control group and even numbers to the treatment group.

\section{Climatic conditions}

The study area experiences tropical wet and dry seasons. The hottest months are March, April, and May (average daily maximum temperature is $32.4{ }^{\circ} \mathrm{C}$ in May). The average daily maximum temperature in the coldest month (December) is $25.1{ }^{\circ} \mathrm{C}$. Total annual rainfall averages $1098.5 \mathrm{~mm}$; the rainy season begins in May and peaks in August/September. The driest periods are late October through April [31]. 
Table 1 Map coordinates, population, and distance to the Niger river of control and experimental villages

\begin{tabular}{|c|c|c|c|c|c|c|c|}
\hline Control villages & Latitude, longitude & Pop. & Dist. (km) & Treated villages & Latitude, longitude & Pop. & Dist. (km) \\
\hline Balandougou & $11.985750,-8.51395$ & $<500$ & $>5$ & Krekrelo & $11.98836,-8.551460$ & $<500$ & $>5$ \\
\hline Madina & $12.05229,-8.373600$ & $<500$ & $<5$ & Sirakele & $11.95466,-8.446560$ & $<500$ & $>5$ \\
\hline Korea & $12.04576,-8.399230$ & $<500$ & $>5$ & Trekrou & $12.068577,-8.314414$ & $>500$ & $<5$ \\
\hline Balala & $11.96599,-8.468310$ & $>500$ & $>5$ & Farabale & $12.03865,-8.424590$ & $<500$ & $>5$ \\
\hline Cissebougou & $12.09628,-8.372850$ & $>500$ & $>5$ & Kignele & $11.96737,-8.397900$ & $>500$ & $<5$ \\
\hline Nianguanabougou & $12.15466,-8.308260$ & $>500$ & $<5$ & Tiko & $12.13444,-8.396860$ & $>500$ & $>5$ \\
\hline Trekrouba & $12.073598,-8.258717$ & $>500$ & $<5$ & Sambadani & $12.14454,-8.316880$ & $>500$ & $<5$ \\
\hline
\end{tabular}

Pop population, Dist distance to river

\section{Malaria vector feeding rate on natural sugar versus attractive sugar bait stations (ASB)}

In a 2-day experiment carried out in 2016, mosquitoes were collected in seven random villages every month with 10 UV CDC light traps (Model 512, John W. Hock Company, Gainesville, Florida, USA), set approximately $5 \mathrm{~m}$ away from 10 different houses in the center of the village, in a rough grid pattern, at least $10 \mathrm{~m}$ away from each other, for $12 \mathrm{~h}$ (from 18:00 to 06:00 h), from April to December 2016. Houses were chosen based on the willingness of the inhabitants to participate. The following day, two bait stations with ASB (no toxin) and with green coloured food dye (Tartrazine 19140, Stern, Natanya, Israel) were placed on every house in the village, hung $1.8 \mathrm{~m}$ above ground on an outside wall, and mosquitoes were collected repeatedly from the same location around these houses for $12 \mathrm{~h}$ with the same CDC UV light traps. Anthrone tests of mosquitoes captured prior to the 1st day of using bait stations showed the percentage of mosquitoes that were feeding on natural sugar sources. Mosquitoes caught by stained bait stations with dye marked bait inside, a night later showed the rate of daily feeding on baits, while the number of unstained yet anthrone positive mosquitoes from the same catch showed the number of mosquitoes that fed on natural sugar sources. For a visual demonstration of colour in the guts of $A n$. gambiae sensu lato (s.l.), see [32].

\section{Testing for sugar and bait feeding}

The sugar content in the gut of a random subset of 350 male and 350 female mosquitoes (50) from each village each month (caught by CDC traps) was determined by a modified cold anthrone test for fructose [33]. In some months, when the catch of mosquitoes was low, the entire catch was tested. In ASB catches, single mosquitoes were taken with forceps from opaque white trap catch-bags and placed into microtitre plates. Workers did not to look into the bag to avoid biased selection. Anthrone test reagent containing $0.15 \% \mathrm{w} / \mathrm{v}$ anthrone
(Sigma, St Louis MO, USA) w/v in $71.7 \%$ sulfuric acid was used. Each mosquito was placed in the well of a flat-bottomed microtitre plate and wetted with $20 \mu \mathrm{l}$ of $100 \%$ ethanol. Aliquots of $200 \mu \mathrm{l}$ reaction solution were added to the wells and the specimens were crushed with a glass rod that was repeatedly washed with water and wiped. Crushed mosquitoes were examined after incubation for $60 \mathrm{~min}$ at $25{ }^{\circ} \mathrm{C}$ and sugar meals were identified by development of blue/green colour. Dye marked bait fed mosquitoes containing food dye were first identified visually with a simple magnifying glass and then re-examined under a dissection microscope. Any blue colour development was considered as positive for sugar. Wells that stayed yellow were considered negative. For a visual indicator of blue colour change see [34].

\section{ATSB composition, ASB composition and bait station construction}

Attractive toxic sugar baits contained the active ingredient dinotefuran $0.11 \%(\mathrm{w} / \mathrm{w}), 1 \%(\mathrm{w} / \mathrm{w})$ BaitStab-a product containing antibacterial and antifungal additives (Westham Innovations LTD., Tel Aviv, Israel), 77\% (w/w) brown sugar, and $22 \%(w / w)$ date syrup. ASB was similar but without toxin and with food dye (Tartrazine 19140, Stern, Natanya, Israel) were provided by Westham Innovations LTD (Tel Aviv, Israel). Bait stations were constructed using a white, rectangular plastic frame with the ASB or ATSB inside with proprietary, mosquito bite and emanation-permeable, black plastic membrane cover and $100 \mathrm{~g}$ of the bait were inserted into the 16 cells of membrane (Westham Innovations LTD, Tel Aviv, Israel). ATSB bait stations (Additional file 2: Fig. S2) were hung (2 per house) in treated villages on May 31st and were left until the end of the project in December.

The AI is an oral toxin, a neonicotinoid [35], with low toxicity to mammals, yet is an acetylcholine agonist affecting the nervous system of insects when ingested. 


\section{Study of the population composition}

Mosquito populations in all the 14 villages were sampled monthly in 2017 from 3 months before the peak mosquito season in April and until 2 months after the peak of the mosquito season in December. Post-collection processing included mosquito identification, age grading, and Plasmodium falciparum sporozoite determination by ELISA. Vector population densities was determined using the following methods.

\section{CDC traps}

In each village, trapping was at the approximate centre where houses were closer together and a near-grid pattern could be obtained for good coverage. 10 CDC UV light traps (Model 512, John W. Hock Company, Gainesville, Florida, USA) were set up outdoors at least $10.0 \mathrm{~m}$ apart, in each village; Their location was in a rough grid pattern next to 10 houses (with permission of the owners) about $5.0 \mathrm{~m}$ away from the house. Traps were set at 18:00 $\mathrm{h}$ and were emptied at 06:00 $\mathrm{h}$. This was conducted in each village for one night per month.

\section{Human landing catches}

The United States Environmental Protection Agency (EPA) guidelines and protocols for the use of human volunteers in HLC experiments were carefully followed [36]. Four volunteers, all male professional entomologists, participated in this study. As part of the informed consent process, the participants were fully advised of the nature and objectives of the test and the potential health risks from exposure to mosquito bites. According to EPA regulations, they were required to avoid alcohol, caffeine, and fragrance products (e.g., perfume, cologne, hairspray, lotion, etc.) during the entire test period. For the mosquito collection tests, volunteers were wearing long trousers and long-sleeved shirts as protection against mosquito bites. One leg of the trousers was rolled up to expose the skin used as the test area. The volunteers were seated motionless in chairs with the exposed leg extended while observation, counting, collecting and recording of mosquitoes was made. The distance between the outdoor volunteers was at least $5 \mathrm{~m}$ and indoor volunteers were located in separate homes. Both indoor and outdoor volunteer locations were switched every $2 \mathrm{~h}$ from 18:00 to $06: 00 \mathrm{~h}$ to eliminate positional bias. Collections were made in two bedrooms of two separate homes per village per month. Mosquitoes for sampling were collected with an entomological hand-vac (Mosquito and Sand fly aspirator model 419; John W. Hock Company, Gainesville, Florida USA) which was used to aspirate landing/biting mosquitoes off of the human volunteer.

\section{Malaise traps}

Ten standard $6 \mathrm{~m}$ malaise traps (Model 3012, John W. Hock Company, Gainesville, Florida, USA) were set up to trap flying adult mosquitoes. These were set at least $10 \mathrm{~m}$ apart and further from the centre of the village where houses were more crowded together. Because these traps are larger than $\mathrm{CDC}$, they were positioned $10 \mathrm{~m}$ from the houses. Traps were set at 18:00 $\mathrm{h}$ and were emptied at 06:00 h.

\section{Pyrethrum spray catches}

Pyrethrum spray catches indoor collections in 10 bedrooms of 10 separate homes per village once per month were conducted according to established protocols [37] to determine the density of resting mosquitoes in homes.

\section{Age determination}

Random samples of 200 females (whenever seasonally possible) collected by each trapping method, were analyzed and the physiological age (number of past ovipositions) was determined by dissection and examination of ovaries in a drop of PBS under a dissecting microscope $10 \times$ to $100 \times$, to expose and count the dilatations in ovarioles [38]. Females were then classified as having undergone either less than 3 gonotrophic cycles or 3 or more cycles.

\section{ELISA testing}

A P. falciparum "sandwich" ELISA was used to test female mosquitoes for sporozoites according to standard protocols [39]. A subsample of 150 randomly selected female An. gambiae s.l. (whenever seasonally possible) collected by each mosquito collection method per village per month, to be processed by ELISA. If the total monthly catch per collection method was less than 150 specimens, all available material was processed by ELISA.

\section{Determination of entomological inoculation rate}

The entomological inoculation rate (EIR) was calculated for mosquitoes caught landing/biting the human volunteers (HLCs). The EIR which is a measure of exposure to infected mosquitoes, is defined as the product of the mosquito biting rate and the sporozoite rate [40]. In this case, the mean daily entomological inoculation rate was calculated by multiplying the overall monthly sporozoite rate determined by ELISA (for all females tested per village from HLC catches) times the mean daily biting pressure from control or treated villages. The biting pressure is defined as the number of biting females per person per night. The monthly inoculation rate was calculated by multiplying the mean daily EIR by 30 . 


\section{Determination of sporozoite infection}

A "sandwich" ELISA was used to test mosquitoes for sporozoites according to the protocol detailed in [39].

\section{Statistical analysis}

For the 2-day experiment, a generalized mixed linear model for a Poisson distributed outcome was used. Because the data exhibited over-dispersion, a negative binomial analysis was used. The fixed effects were month, treatment (Anthrone vs. ASB), and the interaction of month and treatment. Treatment is a repeated measure, and a random error term of village nested in month was used to provide an error term for the repeated measure. A heterogeneous compound symmetric covariance matrix was used to represent the correlated data structure. Model mean percent, standard error, and $95 \%$ CI of the difference between means as well as P-value for a comparison between treatments at each month is presented. Population density had Poisson distribution. Over-dispersion was evident; therefore, a generalized mixed linear model for a negative binomial distribution to analyze the data for each of the three trap types: CDC, Malaise, and PSC was used separately. The model included fixed effects for month (April-December), treatment (control and experimental: a repeated measure over months), and the interaction of month and treatment. A random error term of villages nested within treatment was used for the error term for treatment. A compound symmetric covariance matrix was used to represent the correlated data structure. Model means and standard errors as well as $95 \%$ confidence intervals (CIs) for mean differences are presented for the interaction. P-values are also presented for planned comparisons between treatments at each month. Human landing catches also had a Poisson distribution with over-dispersion; the same analysis plan was used as described above for the traps. The gonadal age and sporozoite infection rate data both had binomial distributions, therefore, a generalized linear mixed model was used to analyze these data. The same model as for the trap data described above was used for both. Model mean and standard error as well as $95 \%$ CIs for mean differences are presented for the interactions. P-values are also presented for planned comparisons between treatments at each month. A general linear model analysis for repeated measures was performed for the monthly EIR rates for indoor and outdoor data separately. The outcome was the EIR; predictors were group (control vs. treatment), month (April-December) and the interaction of group and month. A random effect of village nested within group was included to provide an error term for the repeated measures over month. A compound symmetric covariance matrix was used to represent the correlated structure of the data. Model means and standard errors were reported as well as P-values for comparisons between the groups at each month. The percent reduction in EIR due to the treatment is also included. The two-tailed alpha level was used to determine statistical significance. SAS 9.4 (SAS Institute Inc; Cary NC) was used for all analyses.

\section{Results}

Feeding of malaria vectors on sugar from natural sources compared to feeding from attractive bait stations (ASB)

In the 2-day baseline experiment in 2016, the mean number of females from control villages that fed on natural sugar (i.e. anthrone positive) reached a maximum of $44.9 \%$ of the catch $(22.43 \pm 1.70$ SE per trap) in August, while males maximal sugar feeding of $45.1 \%$ was observed in September (22.57 \pm 1.46 SE per trap) (Fig. 1A, Tables 2, 3). Presentation of ASB bait stations lowered the feeding on natural sources and the percentage of anthrone positive mosquitoes was exceeded by the number of ASB dye-marked mosquitoes (Fig. 1B, Table 2). In the control site the mean number of females feeding on ASB reached a maximum of $35.0 \%$ of the catch $(17.57 \pm 2.37$ SE per trap) in September and they were $17.0 \% 10.86 \pm 1.79 \mathrm{SE}$ per trap in August. The number of males feeding on ASB reached a maximum of $39.9 \%$ of the catch $(15.43 \pm 1.53$ SE per trap) in November while those that fed on natural sugar sources were only $22.3 \%$ in August ( $8.00 \pm 1.21$ SE; Tables 2, 3).

\section{Population density}

The mean population density of male and female mosquitoes in the control and the experimental villages was not significantly different from April to the end of May 2017, which was the pre-treatment monitoring period, (Figs. 1a, b as well as Tables 4A, B and 5). After presenting the ATSB baits, the highest mean catch of CDC light traps, obtained in September, at the control sites was $53.76 \pm 15.60$ SE females, and it dropped by $53.4 \%$ after ATSB treatment to $22.91 \pm 8.00 \mathrm{SE}$. The maximum

(See figure on next page.)

Fig. 1 A Comparison of the mean number of female Anopheles gambiae s.l. ( \pm SE) collected per trap per village from ATSB treated and control villages. The pre-treatment monitoring period was from April until ATSB treatment on May 31st Control and experimental sites were monitored from June to December. a catch of CDC traps; $\mathbf{b}$ catch of Malaise traps; c PSCs. B Comparison of the mean number of male Anopheles gambiae s.I. $( \pm S E)$ collected per trap per village from ATSB treated and from control villages. The pre-treatment monitoring period was from April until ATSB treatment in the 31 of May; All sites were monitored from June to December. a Catch of CDC traps; b Catch of Malaise traps; c PSC catches 

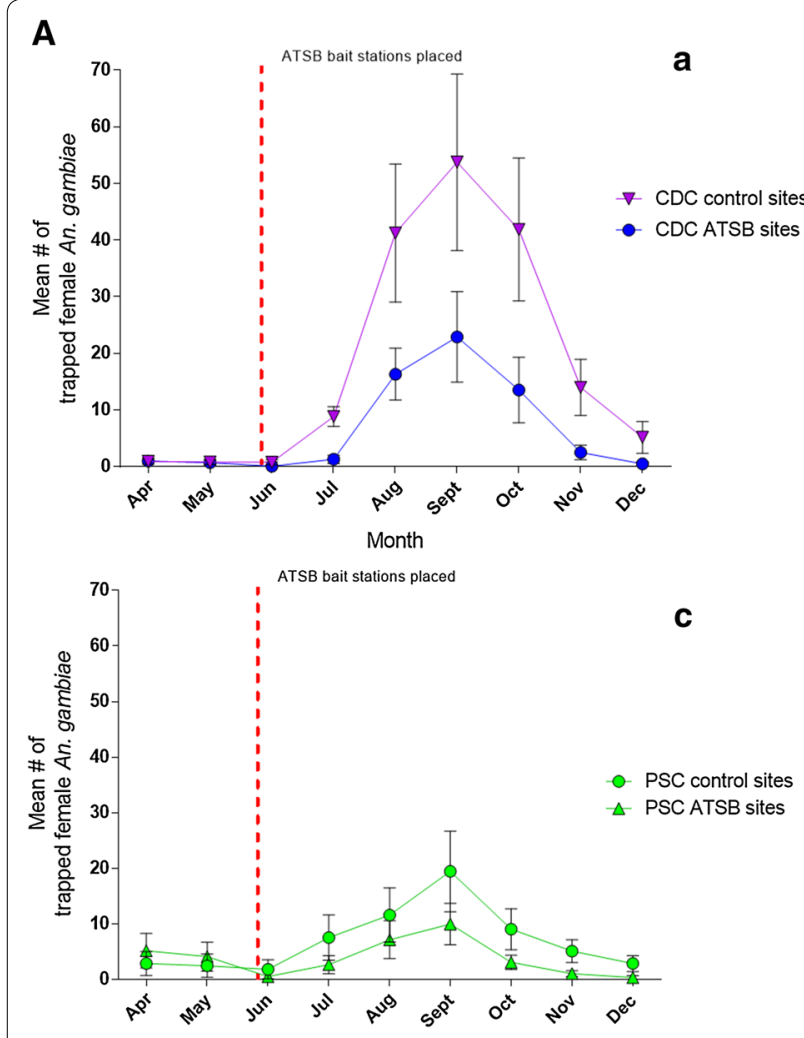

B
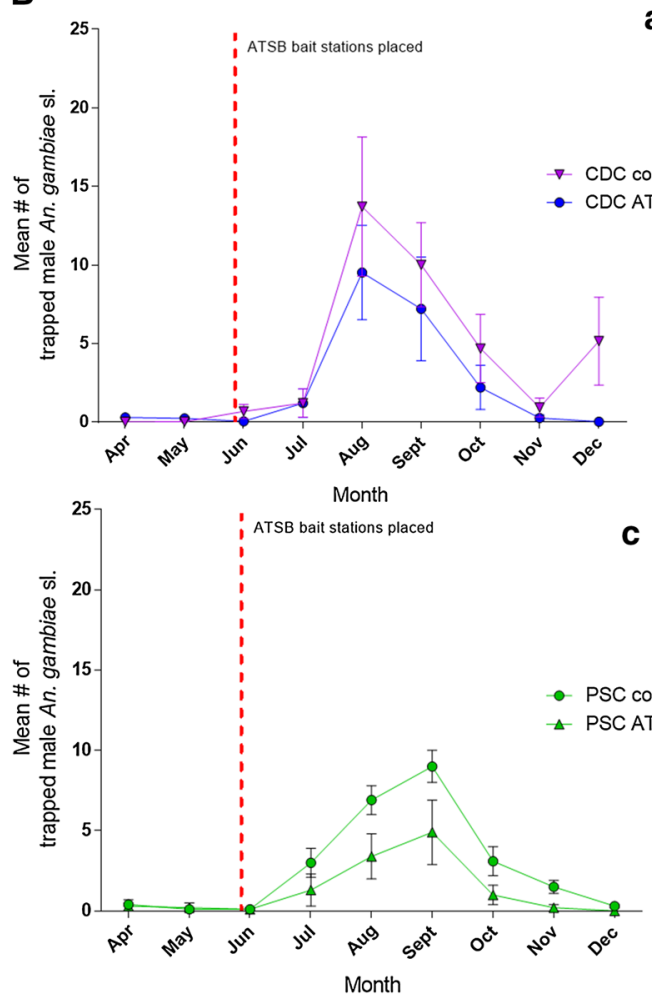

a

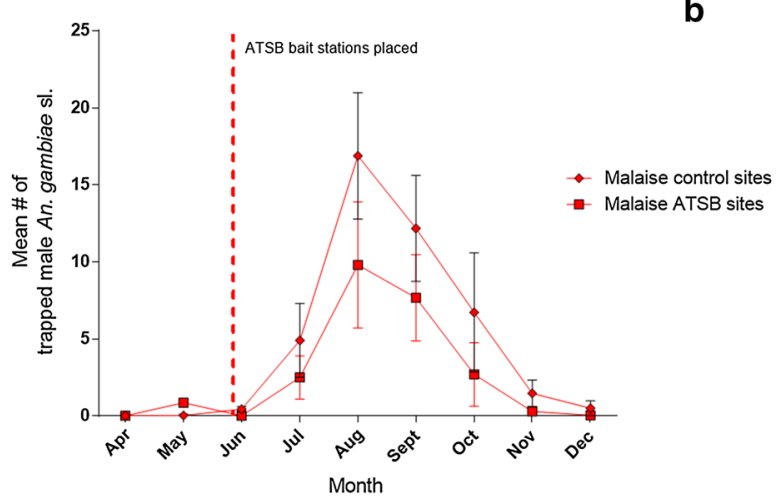

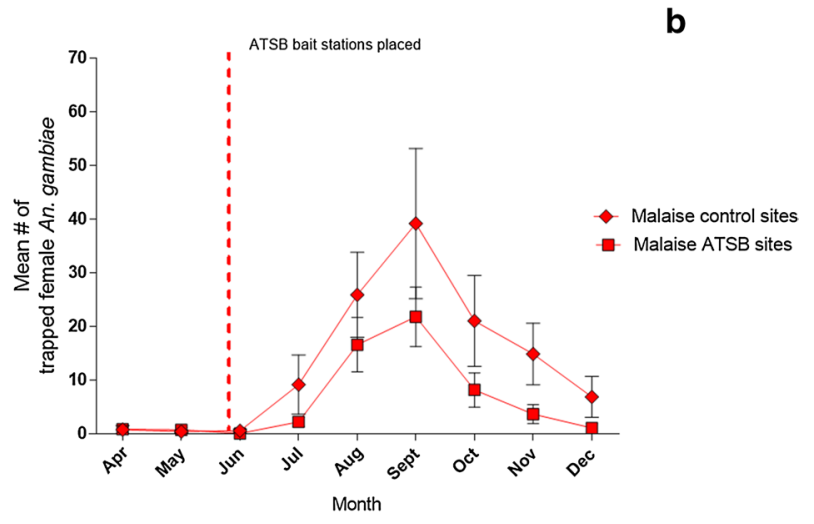

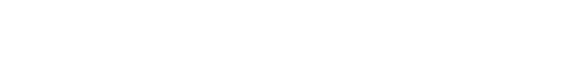


Table 2 Baseline mean ( \pm SE) of male and female An. gambiae that had natural sugar in the gut before presentation of ASB (Day 1)

\begin{tabular}{|c|c|c|c|c|c|}
\hline \multirow[t]{3}{*}{ Month } & \multicolumn{5}{|c|}{ Day 1-Anthrone positive (Natural sugar-fed) } \\
\hline & \multicolumn{3}{|l|}{ Female } & \multicolumn{2}{|l|}{ Male } \\
\hline & $\operatorname{Mean}^{\mathrm{a}} \pm \mathrm{SE}$ & $\%$ of catch & Month & $\operatorname{Mean}^{\mathrm{a}} \pm \mathrm{SE}$ & $\%$ of catch \\
\hline Apr $\mathrm{N}=85$ & $2.57 \pm 1.08$ & 21.10 & Apr $\mathrm{N}=2$ & $0.28 \pm 0.18$ & 0.00 \\
\hline May $N=65$ & $1.17 \pm 0.77$ & 18.90 & May $N=1$ & $0.14 \pm 0.14$ & 0.00 \\
\hline Jun $N=75$ & $3.42 \pm 1.19$ & 32.00 & Jun $N=2$ & $0.28 \pm 0.28$ & 0.00 \\
\hline Jul $N=350$ & $17.71 \pm 3.02$ & 39.70 & Jul $N=140$ & $20.00 \pm 2.43$ & 44.00 \\
\hline Aug $N=350$ & $22.43 \pm 1.70$ & 44.90 & Aug $N=145$ & $20.86 \pm 1.22$ & 41.80 \\
\hline Sept $N=350$ & $20.57 \pm 2.26$ & 41.10 & Sept $N=160$ & $22.57 \pm 1.46$ & 45.10 \\
\hline Oct $N=350$ & $18.86 \pm 1.92$ & 37.70 & Oct $N=125$ & $17.86 \pm 1.71$ & 41.80 \\
\hline Nov $N=300$ & $13.43 \pm 1.64$ & 31.30 & Nov $N=15$ & $2.28 \pm 1.07$ & 28.10 \\
\hline $\operatorname{Dec} N=250$ & $8.14 \pm 2.72$ & 22.70 & $\operatorname{Dec} N=1$ & $0.14 \pm 0.14$ & 0.00 \\
\hline
\end{tabular}

$\mathrm{N}=$ Total pooled sample size from all villages

a Mean positive per village

Table 3 Comparison of the means of males and females feeding on natural sugar versus those feeding on ASB per village ( $\pm \mathrm{SE}$ with $95 \% \mathrm{Cl}$ of the difference between means)

\begin{tabular}{|c|c|c|c|c|c|c|c|c|c|c|c|c|}
\hline \multirow[t]{3}{*}{ Month } & \multicolumn{12}{|c|}{ Day 2-Anthrone positive (Natural sugar-fed) vs. ASB positive } \\
\hline & \multirow{2}{*}{$\begin{array}{l}\text { Female anth } \\
\text { Mean }^{\mathrm{a}} \pm \mathrm{SE}\end{array}$} & \multicolumn{5}{|l|}{ Female ASB } & \multirow[b]{2}{*}{ Month } & \multirow{2}{*}{$\begin{array}{l}\text { Male anth } \\
\text { Mean }^{\mathrm{a}} \pm \mathrm{SE}\end{array}$} & \multicolumn{4}{|l|}{ Male ASB } \\
\hline & & Mean \pm SE & Diff & $95 \%$ & & $P$ value & & & Mean \pm SE & Diff & $95 \% \mathrm{Cl}^{\mathrm{b}}$ & P value \\
\hline Apr $N=88$ & $0.71 \pm 0.29$ & $5.86 \pm 1.65$ & 5.15 & 7.42 & 2.88 & $<0.0001$ & Apr $\mathrm{N}=2$ & $0.00 \pm 0.00$ & $0.14 \pm 0.14$ & 0.14 & 1.320 .00 & 0.5010 \\
\hline May $N=60$ & $0.43 \pm 0$ & $3.71 \pm 1.17$ & 3.28 & 5.55 & 1.01 & 0.0010 & May $N=1$ & & $0.00 \pm 0.00$ & 0.00 & $1.18 \quad 0.00$ & 0.9720 \\
\hline & & & & & & & & & & .00 & $1.18 \quad 0.00$ & 0.9940 \\
\hline Jul N=320 & $7.57 \pm 1.54$ & $16.14 \pm 2.23$ & 8.57 & 10.84 & 6.30 & 0.0050 & Jul $N=310$ & $5.86 \pm 0.63$ & $15.29 \pm 1.19$ & 9.43 & $10.61 \quad 8.25$ & $<0.0001$ \\
\hline Aug $N=350$ & $10.86 \pm 1.79$ & $13.86 \pm 1.75$ & 3.00 & 5.27 & 0.73 & 0.0034 & Aug $N=350$ & $8.00 \pm 1.21$ & $15.43 \pm 1.53$ & 7.43 & $8.61 \quad 6.25$ & $<0.0001$ \\
\hline Sept $N=350$ & $6.71 \pm 1.04$ & $17.57 \pm 2.37$ & 10.86 & 13.13 & 8.59 & $<0.0001$ & Sept $N=350$ & $5.71 \pm 0.61$ & $15.71 \pm 1.34$ & 10.00 & $11.18 \quad 8.82$ & $<0.0001$ \\
\hline Oct $N=350$ & $6.71 \pm 1.13$ & $15.14 \pm 1.99$ & 8.43 & 10.70 & 6.16 & 0.0030 & Oct $N=300$ & $6.00 \pm 0.93$ & $13.86 \pm 1.03$ & 7.86 & $9.04 \quad 6.68$ & $<0.0001$ \\
\hline Nov $N=300$ & $2.71 \pm 0.68$ & $16.00 \pm 2.17$ & 13.29 & 15.56 & 11.02 & $<0.0001$ & Nov $N=60$ & $0.29 \pm 0.18$ & $3.29 \pm 1.04$ & 3.00 & 4.18 & 0.0020 \\
\hline $\operatorname{Dec} N=250$ & $1.71 \pm 0.52$ & $11.57 \pm 1.38$ & 9.86 & 12.13 & 7.59 & $<0.0001$ & $\operatorname{Dec} N=5$ & $0.14 \pm 0.14$ & $0.29 \pm 0.29$ & 0.15 & 1.330 .00 & 0.9980 \\
\hline
\end{tabular}

Catches of the first night post-presentation of ASB (Day 2)

$\mathrm{N}=$ Total pooled sample size from all villages

Diff difference between means

${ }^{a}$ Mean positive per village

${ }^{\text {b }}$ Column $1=$ upper limit, column $2=$ lower limit

mean number of males, in August, was 13.71 $\pm 4.43 \mathrm{SE}$ at the control and at the experimental site the mean was relatively reduced by $57.4 \%$ to $9.52 \pm 3.00 \mathrm{SE}$. The greatest reductions, $94.7 \%$ of females and $94.0 \%$ of males by ATSB treatment, occurred in July. In ATSB treated villages the reduction in malaise trap catches was also consistently high with the maximum mean number of females, reached in September at both sites, lowered to $21.83 \pm 5.55$ SE compared to $39.20 \pm 14.00 \mathrm{SE}$ at the control, a $43.3 \%$ reduction. Males reached their maximum in August and was $9.80 \pm 4.09 \mathrm{SE}$ compared to $16.88 \pm 4.10$
$\mathrm{SE}$ at the control sites, a $41.9 \%$ reduction. The greatest reductions by ATSB as expressed in catches of malaise traps mean catch was $84.0 \%$ smaller in June (females) and no males (100.0\% reduction) were caught in December. PSCs caught maximal number a mean of $9.99 \pm 3.73 \mathrm{SE}$ females in September compared to a mean of $19.46 \pm 7.25$ SE at the control sites, a $48.7 \%$ reduction. The maximum mean number of males $4.90 \pm 2.00 \mathrm{SE}$ was reached in September compared to a mean of $9.00 \pm 1.00 \mathrm{SE}$ at the control sites, a $45.6 \%$ reduction. The greatest reductions in female numbers, in PSC catches was in December 
and males completely disappeared (100.0\% reduction) males (Table 4A, B). Figure 3 shows reductions in female An. gambiae after treatment in May measured by HLC. Indoors, the maximum number of females was caught in September with a mean of $85.36 \pm 3.49 \mathrm{SE}$ at the control sites which was reduced to $68.50 \pm 3.13 \mathrm{SE}$ at the treated sites, a reduction of $19.8 \%$. Outdoors, the maximum number of females at the control sites was a mean of $92.21 \pm 3.6$ SE that were caught in September Their number declined to a mean of $67.93 \pm 3.12 \mathrm{SE}$ at the treated sites, a reduction of $26.3 \%$. The greatest indoor reductions of $67.7 \%$ occurred in December and outdoors the decrease of $80.7 \%$ occurred in June (Table 5).

\section{Age determination}

After ATSB treatment, reductions in the mean number of older females that passed three or more than egg laying cycles were observed in all months. Notably, the highest mean number of $56.00 \pm 8.69$ SE older females was recorded in October in the control villages while in parallel ATSB treated villages their mean number was $1.6 \pm 0.21 \mathrm{SE}$ and such females were completely absent in December (Table 6).

\section{Entomological inoculation rate (EIR) and sporozoite presence in mosquitoes caught on human volunteers}

Following ATSB treatment, there were high reductions of $77.76 \%$ to $100 \%$ indoors and $84.95 \%$ to $100 \%$ outdoors in monthly mean of EIRs (Table 7A, B). In September, the EIR at the control houses indoors was very high at 70.71 while inside the ATSB treated houses it was only 10.71 females. In the same month, outdoors at the control site, the EIR was 57.93 while at the ATSB treated site it was 6.45 females (so many times smaller).

Indoors, there were decreases in monthly P. falciparum sporozoite rates (based on ELISA testing). The mean rate of sporozoite positive mosquitoes indoors in the control villages ranged from 0.84 to $3.8 \%$ while the mean rate of sporozoite positive mosquitoes indoors in the ATSB treatment villages ranged from 0.38 to $0.61 \%$ (Table $7 \mathrm{~A}$ ). In these villages, no sporozoite positive mosquitoes were detected early in the transmission season (June) or at the end of the transmission season (November and December).

Outdoors, the mean rate of sporozoite positive mosquitoes in control villages ranged from 0.59 to $3.5 \%$ with no positive mosquitoes in April, May or December. In treated villages, the outdoor sporozoite infection rate ranged from 0.28 to $0.57 \%$, but no sporozoites were detected from April to July and again in November and December (Table 7A, B).

\section{Sporozoite rate in mosquitoes caught using all trapping methods}

Figure 4 shows the comparison of the mean number of sporozoite positive female mosquitoes from all trapping methods, from control sites compared to treated sites is shown in Fig. 4. Mosquitoes sampled by all trapping methods (CDCs, Malaise, PSCs, and HLCs) and tested by ELISA for sporozoites, were as expected, negative for the first 2 months both in control and treated sites (April and May). From July to October, when catches were highest, sporozoite positive females were reduced by $84.97 \%$ to $95.74 \%$ respectively at the ATSB site compared to the control site (Table 8).

\section{Discussion}

This field trial in southern Mali demonstrated that the use of ATSB had significant diminishing effects on the presence of malaria vectors and consequently on malaria parasite transmission $[7,9]$. The effect was manifested by reductions in vector density and biting pressure and specifically by near elimination of 'old' females that passed at least three egg laying cycles and have a high potential as malaria vectors. Both the sporozoite prevalence, and EIR were also lowered.

The current study used an ATSB system with the AI dinotefuran, a neonicotinoid agonist of the acetylcholine receptor that affects the nervous system [35]. It works when ingested and thereafter has a systemic action with low toxicity mammals [40] which better for the environment.

Estimation of ATSB for mosquito control depended on the earlier observations that sugar meals from natural sources are staple diet for female and male mosquitoes $[19,20]$. In this case, a primary test was to examine the frequency of sugar feeding from natural sources by the local malaria vectors to assess the potential of using ATSB. It was observed that similar proportions of males and females, ranging from $\sim 20$ to $\sim 50 \%$ of the caught mosquitoes, depending on the season, feed on natural sugar sources (males were scarce in the driest months, therefore, their sugar feeding was not recorded in Fig. 1A). After ASB bait stations were hung, the results show that a high proportion of the sugar questing mosquitoes preferred to feed on ASB instead of natural sugar sources (Fig. 1B). The preference of ASB prevailed regardless of season and thus persisted even if there is a seasonal variation in natural sugar sources. The advantage of ASB also shows that the chosen location of the baits in the villages was successful. This demonstrates that ASB, and presumably also ATSB, compete favourably with locally available sugar sources in Mali. Moreover, these results imply that the use of ATSB, a toxin-containing 


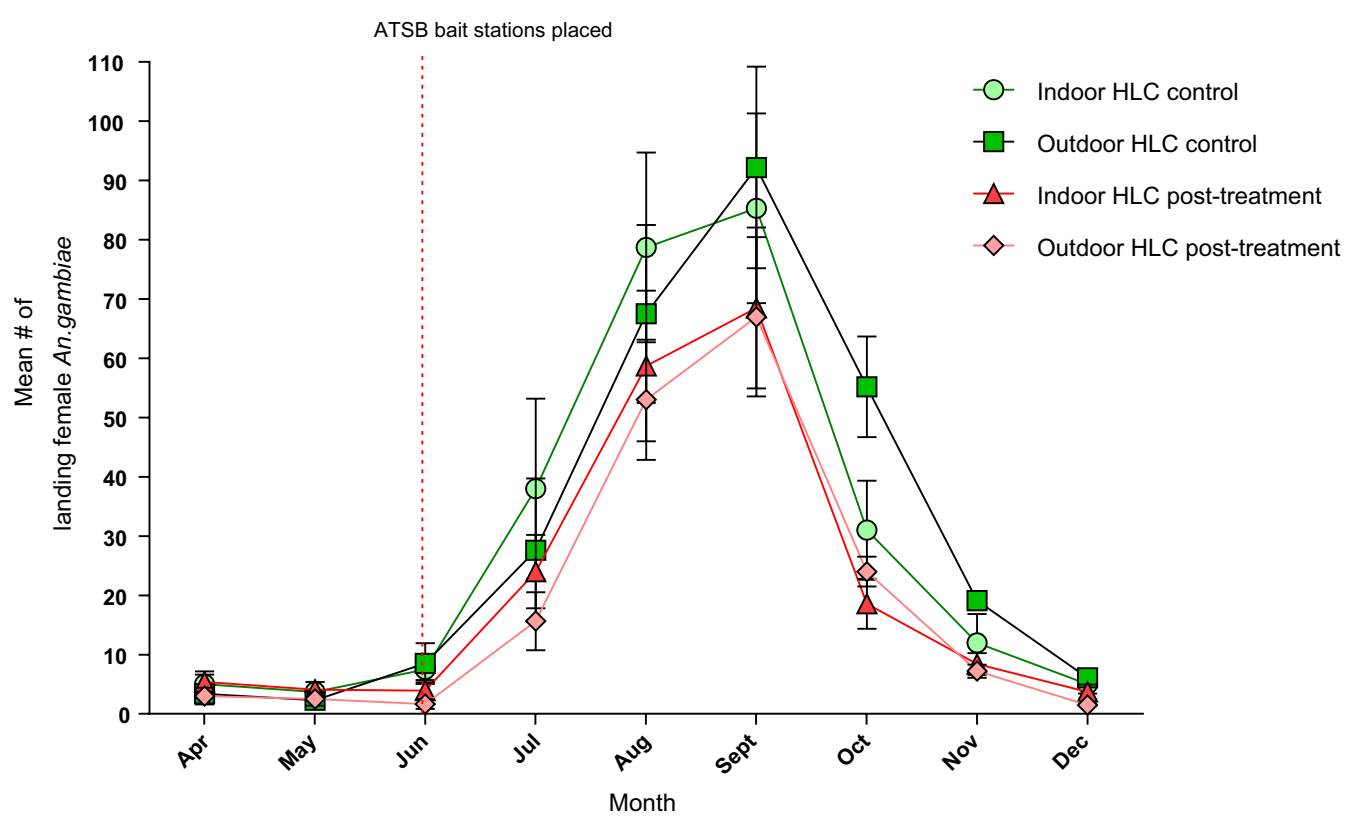

Fig. 2 Landing/biting of Anopheles gambiae females in HLC observations after placement of ATSB bait stations. Data collected indoor and outdoor from ATSB treated villages, and from control villages, were grouped and the mean number of landing/biting per volunteer per night was calculated for each month. a Indoor, b outdoor

ASB in similar environmental conditions can cause persisting decrease of the malaria vector populations.

Indeed, the use of ATSB bait stations outdoors in seven experimental villages was associated with high continuous reductions in population densities of female and male An. gambiae s.l. compared to populations exposed to ASB in seven control villages. These results were repeatedly confirmed in mosquito samples that were captured by different concurrently employed trapping methods. Similar results showing high proportions of ASB marked mosquitoes, as well as ATSB mosquito reductions were obtained in previous small studies in Israel and elsewhere in Mali [21, 27, 41-43]. All types of trapping methods showed some reduced effect of ATSB in the wetter months (August to October).; CDC trap catches were reduced by $\sim 15$ to $20 \%$ while malaise trap and PSC catches were reduced 20 to $30 \%$ during the same months (Figs. 1 and 2a-c). The reduced impacts as population densities increase during the rainy season are likely because the experimental area is on the floodplains of the River Niger and apparently this causes a massive influx of young mosquitoes from rice fields to rice growing villages. It is important to note that in previous studies indicate bait stations aged under field conditions maintain their attraction and mosquito killing activity for 6 months (unpublished data) and so reduced activity of the ATSB unit would not be the cause of reduced ATSB impact. Population reductions in October to December were greater than during the peak months of transmission (July/August), likely because of the observed drying up of neighbouring breeding sites that limited the emergence of new mosquitoes. Another decrease in the presence of mosquitoes occurred indoors and was expressed in yields of HLC and PSC methods. This decrease followed and was caused by the location of bait station outdoors.

Mosquito vectors become infected by feeding on human blood with malaria parasites and they can transmit sporozoites to humans after a 10 to 18 day cycle of growth [44]. Hence only mosquitoes older than 10 days that may carry infective malaria sporozoites can be effective vectors. In previous studies such mosquitoes were defined by evidence that they passed at least three egglaying cycles of 4 days each [44]. As shown in this field study, following the ATSB outdoor treatment the diminishing of the older female group is much greater than that of the general female population. It is hypothesized that this occurs since in the continuous ATSB treatment, the exposure of mosquitoes to the toxin and mosquito mortality increases with age and it is highest in the group of older females, the vectors of malaria. In previous studies the reductions of $>85 \%$ during August to October, when the highest proportions of older females were expected, shows how ATSB distinctly reduces the group of mosquitoes that reach this age and has the direct cumulative effect on older, more dangerous, females that have a 


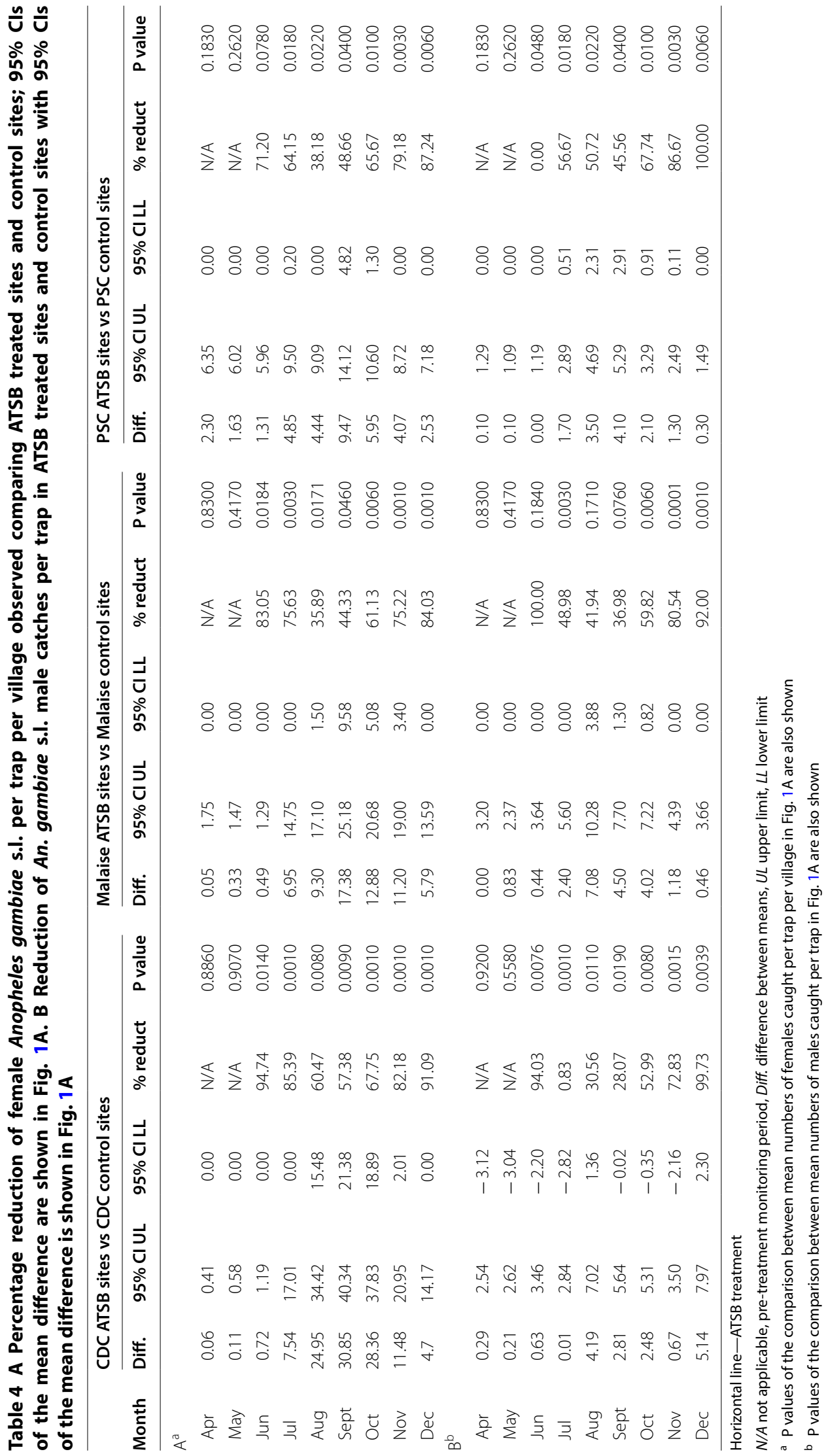


Table 5 Reduction of indoor and outdoor landing/biting of female An. gambiae s.l. per volunteer per night, from control sites compared to ATSB treated sites

\begin{tabular}{|c|c|c|c|c|c|c|c|c|c|c|}
\hline \multirow[t]{2}{*}{ Month } & \multicolumn{5}{|c|}{ Indoor } & \multicolumn{5}{|c|}{ Outdoor } \\
\hline & Diff. & $95 \% \mathrm{Cl}$ UL & $95 \%$ CI LL & $\%$ reduct & $P$ value & Diff. & $95 \% \mathrm{Cl}$ UL & $95 \%$ CI LL & $\%$ reduct & $P$ value \\
\hline Apr & 0.50 & 8.39 & -9.39 & N/A & N/A & 0.43 & 10.63 & -9.77 & N/A & N/A \\
\hline May & 0.43 & 8.46 & -9.32 & N/A & N/A & -0.07 & 10.13 & -10.27 & N/A & N/A \\
\hline Jun & 3.64 & 12.54 & -5.25 & 48.11 & 0.014 & 6.20 & 16.40 & 4.00 & 80.67 & 0.006 \\
\hline Jul & 8.07 & 16.96 & 0.82 & 37.08 & 0.046 & 11.21 & 21.41 & 1.01 & 43.41 & 0.043 \\
\hline Aug & 7.29 & 16.18 & 1.61 & 25.32 & 0.042 & 6.22 & 16.42 & 3.98 & 20.85 & 0.075 \\
\hline Sept & 2.79 & 11.68 & 0.11 & 19.75 & 0.046 & 6.19 & 16.38 & 4.01 & 26.34 & 0.064 \\
\hline Oct & 13.36 & 22.25 & 4.46 & 42.34 & 0.018 & 15.36 & 25.56 & 5.16 & 55.30 & 0.011 \\
\hline Nov & 7.93 & 16.82 & 0.96 & 65.29 & 0.033 & 5.32 & 15.52 & 0.88 & 61.94 & 0.034 \\
\hline Dec & 4.36 & 13.25 & 0.54 & 68.68 & 0.025 & 1.82 & 12.02 & 0.38 & 74.42 & 0.043 \\
\hline
\end{tabular}

(Differences are significant if $\mathrm{P}<0.05$ )

Horizontal line-ATSB treatment

N/A not applicable, pre-treatment monitoring period, Diff. difference in means

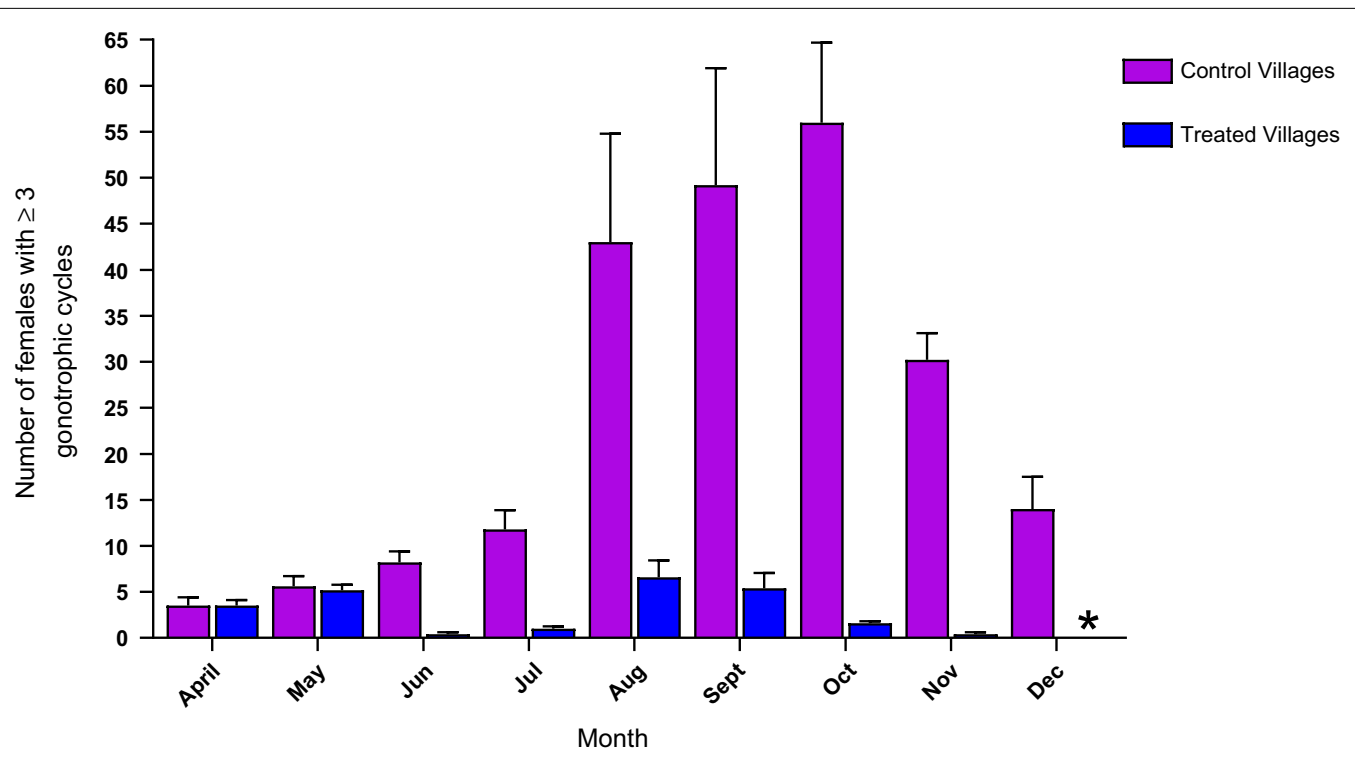

Fig. 3 The mean number per village of Anopheles gambiae s.l. females that passed $\geq 3$ egg laying cycles in control villages and after treatment with ATSB. * Indicates absence of mosquitoes

higher chance of feeding on toxic sugar. These results are in agreement with previous studies $[28,45]$.

The reduction of females infected with sporozoites is an important entomological test of an intervention against malaria and it is of particular interest because it may directly affect human health. The results in this study show how the use of ATSB bait stations outdoors can significantly reduce the number of females that are infective and capable of transmitting sporozoites to humans by bite. After ATSB treatment both indoors and outdoors, the incidence of sporozoite infection in An. gambiae females never exceeded 1\%, and no infection could be detected in the drier months. According to the size of samples mosquito populations are small in these months and this may be the period in which ATSB has the best chance, combined with additional interventions, such as LLINs, to block the transmission cycle of malaria.

The use of ATSB outdoor bait stations was also associated with major reductions in EIRs. In a previous study [46], use of insecticide (permethrin) treated nets (ITS) alone reduced EIRs in Tanzania, Solomon Islands, and Kenya to between 45 and $90 \%$. In the current study, the impact of adding outdoor ATSB bait stations to indoor 
Table 6 Comparison of the number of female An. gambiae s.l. that passed $\geq 3$ egg laying cycles from control sites and ATSB treated sites after the pre-treatment monitoring period

\begin{tabular}{|c|c|c|c|c|c|c|c|c|}
\hline \multirow[t]{2}{*}{ ATSB (N) } & \multirow{2}{*}{$\begin{array}{l}\text { ATSB sites } \\
\text { Mean } \pm \text { SE }\end{array}$} & \multicolumn{7}{|l|}{ Control sites } \\
\hline & & Control (N) & Mean \pm SE & Diff. & $95 \% \mathrm{Cl}$ UL & $95 \%$ CI LL & $\%$ reduct & $P$ value \\
\hline Apr $N=160$ & $3.50 \pm 0.60$ & Apr $N=160$ & $3.50 \pm 0.90$ & 0.00 & 7.21 & -7.21 & N/A & 0.6960 \\
\hline May $N=158$ & $5.20 \pm 0.60$ & May $N=158$ & $5.60 \pm 1.10$ & 0.40 & 7.61 & -6.81 & N/A & 0.4000 \\
\hline Jun $N=220$ & $0.40 \pm 0.21$ & $\operatorname{Jun} N=220$ & $8.20 \pm 1.18$ & 7.80 & 15.01 & 0.59 & 95.12 & 0.1480 \\
\hline $\mathrm{Jul} N=600$ & $1.00 \pm 0.27$ & $\mathrm{Jul} N=600$ & $11.80 \pm 2.13$ & 10.80 & 18.01 & 3.59 & 91.53 & 0.0110 \\
\hline Aug $N=600$ & $6.60 \pm 1.80$ & Aug $N=600$ & $43.00 \pm 11.78$ & 36.40 & 43.61 & 29.19 & 84.65 & $<0.0001$ \\
\hline Sept $N=600$ & $5.40 \pm 1.66$ & Sept $N=600$ & $49.20 \pm 12.70$ & 43.80 & 51.01 & 36.59 & 89.02 & $<0.0001$ \\
\hline Oct $N=600$ & $1.60 \pm 0.21$ & Oct $N=600$ & $56.00 \pm 8.69$ & 54.40 & 61.61 & 47.19 & 97.14 & $<0.0001$ \\
\hline Nov $N=370$ & $0.40 \pm 0.21$ & Nov $N=370$ & $30.20 \pm 2.91$ & 29.80 & 37.01 & 22.59 & 98.68 & $<0.0001$ \\
\hline $\operatorname{Dec} N=135$ & $0.00 \pm 0.00$ & $\operatorname{Dec} N=135$ & $14.00 \pm 3.48$ & 14.00 & 21.21 & 6.79 & 100.00 & 0.9630 \\
\hline
\end{tabular}

N/A not applicable, Diff. difference between means

$\mathrm{N}=$ Total number dissected from CDC, malaise and PSC catches

Horizontal line-ATSB treatment

deltamethrin LLINs compared to indoor deltamethrin LLINs alone, reduced the monthly EIRs indoors by $>80 \%$ when transmission was high and by $100 \%$ when transmission was low (Table 7A). Outdoors, where the baits stations were placed, EIR reductions were at least as high as $92 \%$ and also reached $100 \%$ in low transmission months (Table 7B). Moreover, there was no detectable EIR transmission in the ATSB treatment villages during the very beginning (June, July) or at the end (November, December) of the seasonal transmission period (Table 7A and B). In areas of low transmission, where the annual EIRs are $<1$ to 2 , lowering of the EIR by the proportion achieved in the current study could, on its own be a promising step towards reducing transmission [47]. The reduction in EIRs were greater outdoors than indoors (Table 7A and B). This is not surprising as bait stations were hung outdoors, however, Qualls and colleagues [29] were able to demonstrate significant mosquito PSC reductions by placing bait stations indoors which could be tried alongside the outdoor ones once indoor models become more developed.

Apart from larval source management (LSM) which is not widely used to control malaria [48], current vector control tools are focused indoors. ATSB controls both indoor and outdoor populations, and this becomes even more important in the drive towards malaria elimination as reports of outdoor biting, now known as "residual transmission" [7, 49], is a new recognized set of behaviours exhibited by a mosquito which renders traditional control methods such as IRS and LLINs ineffective. The WHO in its updated malaria terminology guide book, now further recognizes residual transmission as continuing transmission following the enactment of a widely effective malaria programme. ATSB can also be useful in insecticide resistance management and IVM programs as it can use active ingredients with different modes of action because of the direct uptake during feeding.

There are some limitations to this study. First, there was a high degree of variability in trap catch numbers depending on season, and while ATSB had a greater effect on lowering EIR and sporozoite rate in the dry season when mosquito numbers were already low, it was paradoxically difficult to catch enough mosquitoes during this season to demonstrate a major impact on transmission. Second, the toxic sugar baits need to be tested for a second field season so that the results can become predictive and transferable to parts of Africa outside of Mali. Last, we are preparing a paper furthering research that studies the effect of ATSB on organisms outside of mosquitoes or so called "non-targets" such as bees and butterflies. So far, we have found the effect is predominantly on Diptera and the effects on Bees and Butterflies (Lepidoptera) can be mitigated by proper placement of the baits or application of the spray.

\section{Conclusion}

The current large field trial in Mali shows that ATSB is competitive with local sugar sources and its use has significant impacts on population density, age groups proportions, malaria infection incidence in mosquitoes and EIR. It also demonstrates that the use of ATSB bait stations could virtually obstruct transmission in the dry season and could be an effective new class of tool to combat malaria. In order to achieve greater impact, further studies should explore the benefits of using the baits both indoors and outdoors in a range of geographical settings. 


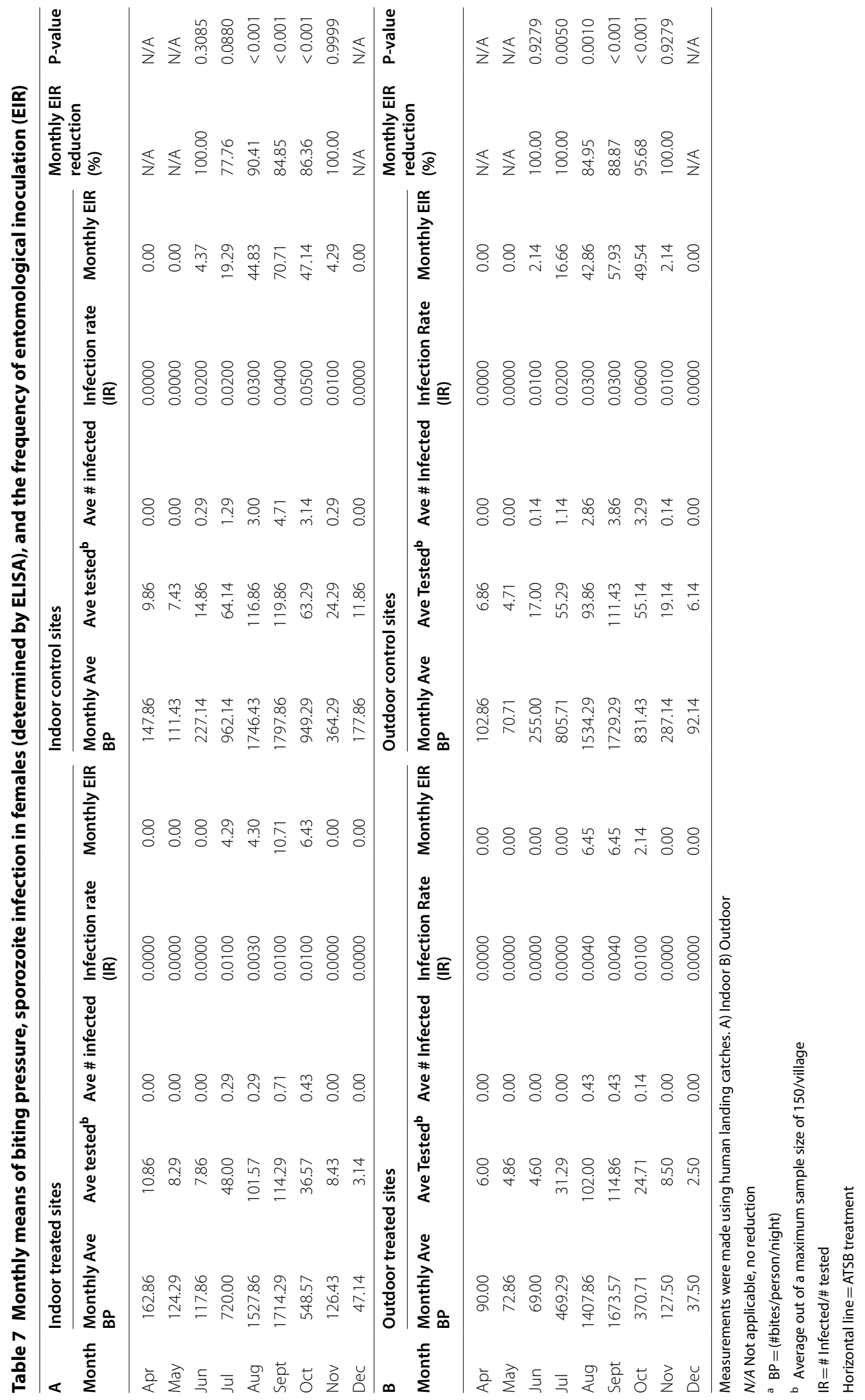




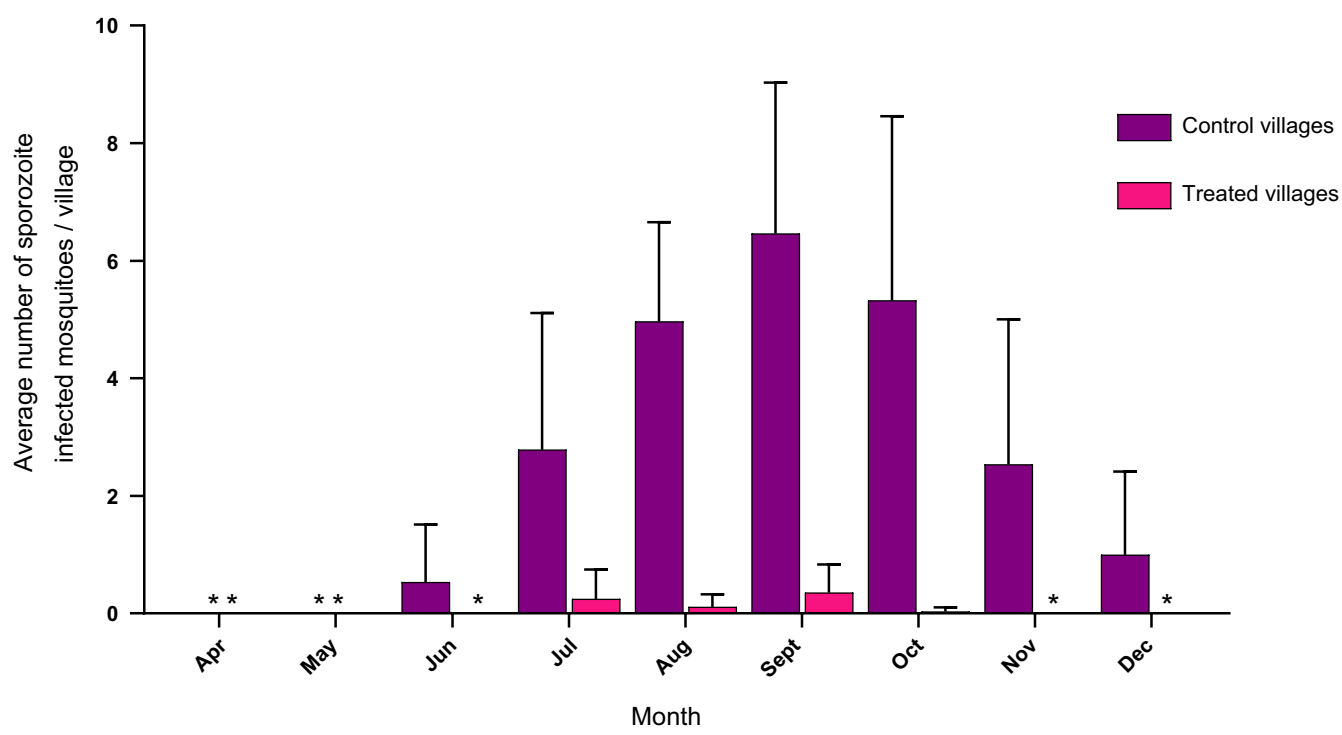

Fig. 4 Mean number per village and month ( \pm SE) of female Anopheles gambiae s.l., collected from all trapping methods and found infected with sporozoites in control villages compared to treated villages

Table 8 Monthly comparison of the mean number of sporozoite infected female An. gambiae s.l. at the ATSB treated sites versus the control sites

\begin{tabular}{|c|c|c|c|c|c|c|c|c|}
\hline $\begin{array}{l}\text { Month } \\
\text { ATSB (N) }\end{array}$ & $\begin{array}{l}\text { ATSB sites } \\
\text { Mean } \pm \text { SE }\end{array}$ & $\begin{array}{l}\text { Month } \\
\text { Control (N) }\end{array}$ & $\begin{array}{l}\text { Control sites } \\
\text { Mean } \pm S E\end{array}$ & Diff. & $95 \% \mathrm{Cl}$ UL & $95 \%$ CI LL & $\%$ reduct & $P$ value \\
\hline Apr $N=120$ & $0.00 \pm 0.00$ & Apr $\mathrm{N}=120$ & $0.00 \pm 0.00$ & 0.00 & N/A & N/A & N/A & N/A \\
\hline May $N=120$ & $0.00 \pm 0.00$ & May $N=120$ & $0.00 \pm 0.00$ & 0.00 & N/A & N/A & N/A & N/A \\
\hline $\operatorname{Jun} N=220$ & $0.00 \pm 0.00$ & $\operatorname{Jun} N=220$ & $0.14 \pm 0.49$ & 0.54 & 3.35 & -2.28 & 100.00 & 0.9996 \\
\hline $\mathrm{Jul} N=600$ & $0.00 \pm 0.25$ & Jul $N=600$ & $1.14 \pm 1.16$ & 2.54 & 5.35 & -0.28 & 100.00 & 0.1035 \\
\hline Aug $N=600$ & $0.43 \pm 0.11$ & Aug $N=600$ & $2.86 \pm 0.85$ & 4.86 & 7.67 & 2.05 & 84.97 & $<0.0001$ \\
\hline Sept $N=600$ & $0.43 \pm 0.24$ & Sept $N=600$ & $3.86 \pm 1.28$ & 6.11 & 8.92 & 3.30 & 88.86 & $<0.0001$ \\
\hline Oct $N=600$ & $0.14 \pm 0.04$ & Oct $N=600$ & $3.29 \pm 1.57$ & 5.29 & 8.10 & 2.48 & 95.74 & $<0.0001$ \\
\hline Nov $N=360$ & $0.00 \pm 0.00$ & Nov $N=360$ & $0.14 \pm 1.24$ & 2.54 & 5.35 & -0.28 & 100.00 & 0.1035 \\
\hline $\operatorname{Dec} N=120$ & $0.00 \pm 0.00$ & $\operatorname{Dec} N=120$ & $0.00 \pm 0.71$ & 1.00 & 3.81 & -1.81 & N/A & 0.9646 \\
\hline
\end{tabular}

N/A Not applicable, no reduction, Diff. difference between treatment and control means

Horizontal line-ATSB treatment

$\mathrm{N}=$ Total number tested from CDC, malaise, PSC and HLC catches

\section{Supplementary information}

Supplementary information accompanies this paper at https://doi. org/10.1186/s12936-020-3132-0.

Additional file 1: Fig. S1. Map of the positions of the 14 study villages and their relation to the Niger River. Generated by Google Maps Professional.

Additional file 2: Fig. S2. A schematic presentation of bait station with a magnification of the permeable, black plastic membrane penetrable enough for mosquitoes to feed. B) Photo of the bait station hung on the outer wall of a house.

\section{Abbreviations}

ASB: Attractive sugar bait; ATSB: Attractive toxic sugar baits; CDC: Center for Disease Control; Cl: Confidence interval; EIR: Entomological inoculation rate; EPA: Environmental Protection Agency; HLC: Human landing catch; LLINS: Long-lasting insecticidal nets; PSC: Pyrethrum spray catch; WHO: World Health Organization.

\section{Acknowledgements}

The authors would like to thank the community members in the 14 villages in Mali for their participation and Ms. Arlene Lahti M.Sc. for reviewing this manuscript. Thanks also to Andrè Wilke of the Division of Environment \& Public Health, Department of Public Health Sciences University of Miami Miller School of Medicine for his assistance in drawing the study site map. 


\section{Authors' contributions}

GCM, YS, RAD and JCB conceived and designed the study. GCM, RAD, ASK MMT, SFT, JV, RB, PG, VDK, SD, and EER supervised and carried out the field work. AJ drafted the manuscript. SM, RX assisted in drafting the manuscript. $\mathrm{KLA}$ and JB carried out statistical analysis. All authors read and approved the final manuscript.

\section{Funding}

This study was supported by the Innovative Vector Control Consortium. This project was also supported by NIH Grants U19Al129387 and R01Al100968. The funders had no role in study design, data collection and analysis, decision to publish, or preparation of the manuscript. The content is solely the responsibility of the authors and does not necessarily represent the official views of the National Institutes of Health. The authors declare that no competing interests exist in relation to this project.

\section{Availability of data and materials}

All data generated and analysed during this study are included in this published article.

\section{Ethics approval and consent to participate}

All the work involving the use of human volunteers in experimental homes and HLCs was approved by the ethical review committee of the University of Sciences Techniques and Technology (IRB 2015/107/CE/FMPOS).

\section{Consent for publication}

All authors contributed to the interpretation of the data and approved the final manuscript.

\section{Competing interests}

The authors declare that they have no competing interests.

\section{Author details}

${ }^{1}$ Malaria Research and Training Centre, Faculty of Medicine, Pharmacy and Odonto-Stomatology, University of Sciences, Techniques and Technology of Bamako, BP 1805, Bamako, Mali. ${ }^{2}$ Department of Zoology, Tel Aviv University, 61500 Tel Aviv, Israel. ${ }^{3}$ Department of Microbiology and Molecular Genetics, IMRIC, Kuvin Centre for the Study of Infectious and Tropical Diseases, Faculty of Medicine, Hebrew University, 91120 Jerusalem, Israel. ${ }^{4}$ Department of Public Health Sciences, Miller School of Medicine, University of Miami, Miami, FL 33136, USA. 5 SNSB-Zoologische Staatssammlung, 81247 Munich, Germany. ${ }^{6}$ Anastasia Mosquito Control District, 120 EOC, St. Augustine, FL 32092, USA. ${ }^{7}$ Pan-African Mosquito Control Association, P.O. Box 54840-00200, Nairobi, Kenya. ${ }^{8}$ MRC Tropical Epidemiology Group, London School of Hygiene and Tropical Medicine, London WC1E 7HT, UK. ${ }^{9}$ Institute of Molecular Biology and Biotechnology, Foundation for Research and TechnologyHellas, 70013 Heraklion, Greece. ${ }^{10}$ Pesticide Science Laboratory, Department of Crop Science, Agricultural University of Athens, 11855 Athens, Greece.

Received: 9 September 2019 Accepted: 22 January 2020 Published online: 14 February 2020

\section{References}

1. Sinka ME, Bangs MJ, Manguin S, Rubio-Palis Y, Chareonviriyaphap T, Coetzee $M$, et al. A global map of dominant malaria vectors. Parasit Vectors. 2012;5:69.

2. WHO. World malaria report 2018. Geneva: World Health Organization; 2018.

3. malERA Consultative Group on Vector Control. A research agenda for malaria eradication: vector control. PLoS Med. 2011;8:e1000401.

4. Hemingway J, Shretta R, Wells TN, Bell D, Djimdé AA, Achee N, et al. Tools and strategies for malaria control and elimination: what do we need to achieve a grand convergence in malaria? PLoS Biol. 2016;14:e1002380.

5. Greenwood B. New tools for malaria control — using them wisely. J Infect. 2017;74(Suppl 1):S23-6.

6. Beier JC, Keating J, Githure JI, Macdonald MB, Impoinvil DE, Novak RJ. Integrated vector management for malaria control. Malar J. 2008;7(Suppl 1):S4.
7. Killeen GF. Characterizing, controlling and eliminating residual malaria transmission. Malar J. 2014;13:330.

8. Fillinger $U$, Lindsay SW. Larval source management for malaria control in Africa: myths and reality. Malar J. 2011;10:353.

9. Vontas J, Moore S, Kleinschmidt I, Ranson H, Lindsay S, Lengeler C, et al. Framework for rapid assessment and adoption of new vector control tools. Trends Parasitol. 2014:30:191-204.

10. Benelli G, Beier JC. Current vector control challenges in the fight against malaria. Acta Trop. 2017:174:91-6.

11. Ranson H, Lissenden N. Insecticide resistance in African Anopheles mosquitoes: a worsening situation that needs urgent action to maintain malaria control. Trends Parasitol. 2016;32:187-96.

12. Amek N, Bayoh N, Hamel M, Lindblade KA, Gimnig JE, Odhiambo F, et al. Spatial and temporal dynamics of malaria transmission in rural Western Kenya. Parasit Vectors. 2012;5:86

13. Moiroux N, Damien GB, Egrot M, Djenontin A, Chandre F, Corbel V, et al. Human exposure to early morning Anopheles funestus biting behavior and personal protection provided by long-lasting insecticidal nets. PLoS ONE. 2014;9:e104967.

14. Sougoufara S, Diédhiou SM, Doucouré S, Diagne N, Sembène PM, Harry $\mathrm{M}$, et al. Biting by Anopheles funestus in broad daylight after use of longlasting insecticidal nets: a new challenge to malaria elimination. Malar J. 2014;13:125.

15. Straif SC, Beier JC. Effects of sugar availability on the blood-feeding behavior of Anopheles gambiae (Diptera: Culicidae). J Med Entomol. 1996;33:608-12.

16. Impoinvil DE, Kongere JO, Foster WA, Njiru BN, Killeen GF, Githure J, et al. Feeding and survival of the malaria vector Anopheles gambiae on plants growing in Kenya. Med Vet Entomol. 2004;18:108-15.

17. Gary RE, Foster WA. Anopheles gambiae feeding and survival on honeydew and extra-floral nectar of peridomestic plants. Med Vet Entomol. 2004;18:102-7.

18. Manda H, Gouagna LC, Nyandat E, Kabiru EW, Jackson RR, Foster WA, et al. Discriminative feeding behaviour of Anopheles gambiae s.s. on endemic plants in western Kenya. Med Vet Entomol. 2007;21:103-11.

19. Yuval B. The other habit: sugar feeding by mosquitoes. Bull Soc Vector Ecol. 1992;17:150-6.

20. Foster WA. Mosquito sugar feeding and reproductive energetics. Annu Rev Entomol. 1995;40:443-74.

21. Schlein Y, Müller GC. An approach to mosquito control: using the dominant attraction of flowering Tamarix jordanis trees against Culex pipiens. J Med Entomol. 2008:45:384-90.

22. Müller GC, Junnila A, Qualls W, Revay EE, Kline DL, Allan S, et al. Control of Culex quinquefasciatus in a storm drain system in Florida using attractive toxic sugar baits. Med Vet Entomol. 2010;24:346-51.

23. Müller GC, Junnila A, Schlein Y. Effective control of adult Culex pipiens by spraying an attractive toxic sugar bait solution in the vegetation near larval habitats. J Med Entomol. 2010;47:63-6.

24. Schlein Y, Müller GC. Diurnal resting behavior of adult Culex pipiens in an arid habitat in Israel and possible control measurements with toxic sugar baits. Acta Trop. 2012;124:48-53.

25. Junnila A, Revay EE, Müller GC, Kravchenko V, Qualls WA, Allen SA, et al. Efficacy of attractive toxic sugar baits (ATSB) against Aedes albopictus with garlic oil encapsulated in beta-cyclodextrin as the active ingredient. Acta Trop. 2015;152:195-200.

26. Revay EE, Schlein Y, Tsabari O, Kravchenko V, Qualls W, De-Xue R, et al. Formulation of attractive toxic sugar bait (ATSB) with safe EPA-exempt substance significantly diminishes the Anopheles sergentii population in a desert oasis. Acta Trop. 2015;150:29-34.

27. Müller GC, Beier JC, Traore SF, Toure MB, Traore MM, Bah S, et al. Successful field trial of attractive toxic sugar bait (ASTB) plant-spraying methods against malaria vectors in the Anopheles gambiae complex in Mali, West Africa. Malar J. 2010;9:210

28. Beier JC, Müller GC, Gu W, Arheart KL, Schlein Y. Attractive toxic sugar bait (ATSB) methods decimate populations of Anopheles malaria vectors in arid environments regardless of the local availability of favoured sugarsource blossoms. Malar J. 2012;11:31.

29. Qualls WA, Müller GC, Traore SF, Traore MM, Arheart KL, Doumbia S, et al. Indoor use of attractive toxic sugar bait (ATSB) to effectively control malaria vectors in Mali, West Africa. Malar J. 2015;14:301. 
30. Qualls WA, Müller GC, Revay EE, Allan SA, Arheart KL, Beier JC, et al. Evaluation of attractive toxic sugar bait (ATSB) — barrier for control of vector and nuisance mosquitoes and its effect on non-target organisms in subtropical environments in Florida. Acta Trop. 2014;131:104-10.

31. Climates to travel: world climate guide. 2018. https://www.climatesto travel.com/climate/mali. Accessed 14 Feb 2018.

32. Kline DL, Muller GC, Junnila A, Xue RD. Attractive toxic sugar baits (ATSB): a novel vector management tool. In: Advances in the biorational control of medical and veterinary pests. American Chemical Society; 2018. pp. 63-73.

33. Schlein Y, Jacobson RL. Mortality of Leishmania major in Phlebotomus papatasi caused by plant feeding of sand flies. Am J Trop Med Hyg. 1994:50:20-7.

34. Sissoko F, Junnila A, Traore MM, Traore SF, Doumbia S, Dembele SM, et al. Frequent sugar feeding behavior by Aedes aegypti in Bamako, Mali makes them ideal candidates for control with attractive toxic sugar baits (ATSB). PLOS ONE. 2019;14:e0214170.

35. Tomizawa M, Yamamoto I. Structure-activity relationships of nicotinoids and imidacloprid analogs. J Pestic Sci. 1993;18:91-8.

36. United States Environmental Protection Agency (EPA). Product performance test guidelines OPPTS 810.3700: insect repellents to be applied to human skin. 2010;712-C-10-00.

37. WHO. Manual on practical entomology. Parts 1 and 2. Methods and techniques No. 13. Geneva: World Health Organization; 1975.

38. Detinova TS, Bertram DS, WHO. Age-grouping methods in Diptera of medical importance, with special reference to some vectors of malaria. Monograph Series 47. Geneva: World Health Organization; 1962.

39. Beier MS, Schwartz IK, Beier JC, Perkins PV, Onyango F, Koros JK, et al. Identification of malaria species by ELISA in sporozoite and oocyst infected Anopheles from western Kenya. Am J Trop Med Hyg. 1988:39:323-7.

40. Beier JC. Vector incrimination and entomological inoculation rates. In: Malaria methods and protocols. Humana; 2002. p. 3-11.
41. Müller GC, Schlein Y. Sugar questing mosquitoes in arid areas gather on scarce blossoms that can be used for control. Int J Parasitol. 2006;36:1077-80

42. Müller GC, Schlein Y. Efficacy of toxic sugar baits against adult cisterndwelling Anopheles claviger. Trans R Soc Trop Med Hyg. 2008;102:480-4.

43. Müller GC, Kravchenko VD, Schlein Y. Decline of Anopheles sergentii and Aedes caspius populations following presentation of attractive, toxic (Spinosad), sugar bait stations in an oasis. J Am Mosq Control Assoc. 2008:24:147-9.

44. Gillies MT. The duration of the gonotrophic cycle in Anopheles gambiae and Anopheles funestus, with a note on the efficiency of hand catching. East Afr Med J. 1953;30:129-35.

45. Gu W, Müller G, Schlein Y, Novak RJ, Beier JC. Natural plant sugar sources of Anopheles mosquitoes strongly impact malaria transmission potential. PLOS ONE. 2011;6:e15996.

46. Shaukat AM, Breman JG, McKenzie FE. Using the entomological inoculation rate to assess the impact of vector control on malaria parasite transmission and elimination. Malar J. 2010;9:122.

47. Beier JC, Killeen GF, Githure Jl. Entomologic inoculation rates and Plasmodium falciparum malaria prevalence in Africa. Am J Trop Med Hyg. 1999;61:109-13.

48. Choi L, Wilson A. Larviciding to control malaria. Cochrane Database Syst Rev. 2017;7:CD012736.

49. Chaccour C, Killeen GF. Mind the gap: residual malaria transmission, veterinary endectocides and livestock as targets for malaria vector control. Malar J. 2016;15:24.

\section{Publisher's Note}

Springer Nature remains neutral with regard to jurisdictional claims in published maps and institutional affiliations.
Ready to submit your research? Choose BMC and benefit from:

- fast, convenient online submission

- thorough peer review by experienced researchers in your field

- rapid publication on acceptance

- support for research data, including large and complex data types

- gold Open Access which fosters wider collaboration and increased citations

- maximum visibility for your research: over $100 \mathrm{M}$ website views per year

At BMC, research is always in progress.

Learn more biomedcentral.com/submissions 